Erratum

\title{
Erratum to "Maximum Phonation Time in People with Obesity Not Submitted or Submitted to Bariatric Surgery"
}

\author{
Ana Laura Ferreira Fonseca, ${ }^{1}$ Wilson Salgado Jr., ${ }^{2}$ and Roberto Oliveira Dantas $\mathbb{D D}^{1}$ \\ ${ }^{1}$ Department of Medicine, Ribeirão Preto Medical School, University of São Paulo, Av. Bandeirantes 3900 Ribeirão Preto SP, \\ São Paulo 14049-900, Brazil \\ ${ }^{2}$ Department of Surgery and Anatomy, Ribeirão Preto Medical School, University of São Paulo, \\ Av. Bandeirantes 3900 Ribeirão Preto SP, São Paulo 14049-900, Brazil
}

Correspondence should be addressed to Roberto Oliveira Dantas; rodantas@fmrp.usp.br

Received 23 June 2020; Accepted 24 June 2020; Published 1 September 2020

Copyright (C) 2020 Ana Laura Ferreira Fonseca et al. This is an open access article distributed under the Creative Commons Attribution License, which permits unrestricted use, distribution, and reproduction in any medium, provided the original work is properly cited.

In the article titled "Maximum Phonation Time in People with Obesity Not Submitted or Submitted to Bariatric Surgery" [1], there was an error in author name, where "Ana Luara Ferreura Fonseca" should be corrected to "Ana Laura Ferreira Fonseca." The corrected author name is shown in the author list above.

\section{References}

[1] A. L. Ferreira Fonseca, W. Salgado Jr., and R. O. Dantas, "Maximum phonation time in people with obesity not submitted or submitted to bariatric surgery," Journal of Obesity, vol. 2019, Article ID 5903621, 5 pages, 2019. 